\title{
Natural irrigation solutions in endodontics
}

\author{
(D) Betül Tekin, (1) Kadriye Demirkaya \\ University of Health Sciences Turkey, Gülhane Faculty of Dentistry, Department of Endodontics, Ankara, Turkey
}

\section{Date submitted: \\ 05.12.2019}

Date accepted:

20.02.2020

Online publication date:

15.09.2020

\section{Corresponding Author:}

Betül Tekin, MD, University of Health Sciences Turkey, Gülhane Faculty of Dentistry, Department of Endodontics, Ankara, Turkey

betulsuntarbetul@gmail.com

ORCID:

orcid.org/0000-0001-6365-9986

Keywords: Root canal irrigation, root canal irrigants, therapeutic Irrigation

\begin{abstract}
It has been discovered that due to the complex structure of root canals, mechanical instrumentation alone was not sufficient to remove microorganisms settled in the pulp cavity and the infected or non-infected pulp residues that could be nutrients for those bacteria. Therefore, it has been highlighted that the irrigation process carried out with the irrigation solutions that enable root canal disinfection by removing those microorganisms and tissue residues without damaging the surrounding tissues is extremely important. Although various irrigation solutions used for this purpose allow for a significant reduction in the bacterial population in infected root canals, in many clinical cases, some bacteria remain and proliferate, thereby cause re-infection of the canal and failure of the root canal treatment. In order to increase the success of root canal treatments, research studies to find an ideal irrigation agent are still underway. In recent years, the interest in the use of natural products has increased significantly. Conventional irrigation solutions currently in use today, however, are defined as synthetic chemical agents. As synthetic agents have certain disadvantages such as lacking the characteristic properties of an ideal irrigation material alone, failing to create sufficient effect at high concentrations, having potential side effects, causing drug interactions in combined use and not responding safety concerns, naturally sourced alternatives for endodontic use have begun to be investigated. In this context, this review aims to present current literature information about the known and developing natural root canal irrigation agents besides the known root canal irrigation agents.
\end{abstract}

\section{Introduction}

One primary objective in the root canal treatments is to ensure chemomechanical removal of the microorganisms and organic/inorganic tissue residues from the infected root canals. Studies in the literature report that due to the structure of the root canals, mechanical instrumentation alone could not perform a satisfying cleaning in the canal. In ex vivo and clinical studies, some areas have remained unreached and infected, thus irrigation has played a key role in the achievement of root canal treatments $(1,2)$.

Irrigation is a process performed to make the mechanical preparation easier through lubrication by wetting the root canals with liquids of different types and concentrations, and to ensure the disinfection of the root canals by removing the organic/ inorganic debris, infected pulp tissue, microorganisms, soft and hard tissue residues from the root canals both physically and chemically. An irrigation solution of optimal quality that can completely clean the root canals alone is not still available, and although there are new developments in the relevant field of research, a solution much closer to the ideal quality has not been developed yet.

Having many of the properties expected from root canal irrigation solutions, sodium hypochlorite $(\mathrm{NaOCl})$ is the most ideal and the most widely used agent among all washing irrigation agents developed in recent years. $\mathrm{NaOCl}$ can be used at different concentrations but is commonly used in root canal treatments at concentrations from $0.5 \%$ to $6 \%$. Besides its excellent properties such as high antimicrobial activity, satisfying tissue dissolving, accessibility, and a relatively lower cost, $\mathrm{NaOCl}$ also has certain disadvantages like failing to remove the smear layer alone, causing a bad smell, emphysema, possible allergic reactions, and toxic effect on the surrounding tissues. Recently, it has been discovered that it has a detrimental impact on dentin elasticity and bending resistance, as well $(3,4)$.

Another irrigation solution, chlorhexidine gluconate $(\mathrm{CHX})$, is reported to show a bactericidal effect by causing coagulation of intracellular components at high concentrations, while it has shown a bacteriostatic effect at low concentrations $(4,5)$. For 
the bacteriostatic effect, 0.1 to $0.2 \%$ aqueous solutions are recommended in the oral cavity, while $2 \%$ is the concentration of root canal irrigation solutions usually found in the endodontic literature (3). Although $\mathrm{CHX}$ is widely used in root canal disinfection due to its high antimicrobial activity, its efficacy in dissolving tissues is lower than $\mathrm{NaOCI}(4,5)$.

Ethylenediaminetetraacetic acid (EDTA), a chelating agent, is another product which is commonly used as an irrigation solution because of its utilization in the instrumentation of narrow and calcified canals and its ability to facilitate the preparation, to remove the smear layer formed in the root canal, and to ensure a better adaptation of the duct filling by increasing the permeability of dentin (6).

Mixture of tetracycline, acid, and detergent (MTAD), which contains various proportions of doxycycline, citric acid, and surface-active detergent, is the first endodontic solution capable of removing the smear layer and ensuring root canal disinfection at the same time (7).

Tetraclean is also a common irrigation solution, the combination of which is similar to the MTAD (antibiotic, citric acid, detergent), but the proportions of the ingredients are different. QMIX solution consisting of EDTA, CHX and a detergent is among the recommended products for irrigation (8).

Hydrogen peroxide, which is known for its poor antibacterial effect, causes foaming during the evaporation of oxygen when used in combination with $\mathrm{NaOCl}$ and is not often recommended as a routine solution due to those limitations, iodine potassium iodide, which has possible allergic reaction risks and causes stainings in dentin, and the HEBP (etidronic acid), which is thought to be the only chelator that can be used together with $\mathrm{NaOCl}$ without affecting its antimicrobial activity, are included among the irrigation solutions currently in use $(9,10)$.

Those irrigation solutions commonly used today are synthetic chemical products and do not have the ideal properties of an irrigation material alone. Considering the undesirable and insufficient properties of the existing solutions, the continuous increase in the number of strains resistant to solutions, and the side effects of synthetic drugs; researchers have been seeking for remedies with the herbal and natural products, and in the studies, it has been shown that the natural alternatives for endodontic practice are quite promising (11).

The purpose of this literature review is to present a compilation of the data on the use and efficacy of herbal irrigation solutions besides conventional routine irrigation solutions applied to the root canal.

\section{Naturally Sourced Irrigation Solutions}

\section{Vinegar}

Vinegar is commonly used in alternative cures for cancer, cardiovascular diseases, and body or joint aches, also to control diabetes, cholesterol, blood glucose, blood pressure levels, and weight loss (12-14). Functioning as an antiseptic agent due to its medicinal properties, it has been used in the treatment of infected wounds (15). While distilled white vinegar and grape vinegar are mainly composed of acetic acid, apple cider vinegar consists of malic acid with therapeutic properties (16). In recent studies, the use of apple cider vinegar as an auxiliary solution for chemomechanical cleaning of the root canals has also been investigated and has attracted attention with promising results in comparison to traditional endodontic irrigators such as NAOCl and EDTA (17). As vinegar is easily accessible and lower in cost and it shows an interaction mechanism similar to EDTA on mineralized tissue, pioneering studies have been conducted to evaluate its effect on endodontic microorganisms, its physicochemical properties, and its role in periapical tissue healing.

Apple cider vinegar is capable of removing the smear layer consisting of organic and inorganic components that obstruct the dentinal tubule entrances (18-21). It has also been proven to have a bactericidal effect against microorganisms that are frequently associated with endodontic infections such as Staphylococcus aureus and Enterococcus faecalis (20). In 2018, Yagnik et al. (22) investigated the antimicrobial effects of apple cider vinegar on Candida albicans, S. aureus and Escherichia coli. In order to reduce their growth, 1/50 dilution of apple cider vinegar solution is sufficient for $E$. coli (minimum inhibition concentration: $62 \mu \mathrm{g} /$ $\mathrm{mL}$ ), a 1/2 dilution needs to be made for $S$. aureus (MIC: 125 $\mu \mathrm{g} / \mathrm{mL}$ at a $\% 2.5$ acidity), and undiluted apple vinegar [minimum inhibition concentration (MIC): $250 \mu \mathrm{g} / \mathrm{mL}$ at $5 \%$ acidity] has been found to be sufficient for $C$. albicans.

Apple cider vinegar is a highly biocompatible material. It is thought that the high rate of malic acid in its combination contributes to the repair process in the periapical region (15). Malic acid is a substance increasing the resistance of an organism. Because it is one of the acids involved in the Krebs cycle, a reaction is responsible for the production of energy in cells. In addition, apple cider vinegar has significant medical potential as it includes vital minerals (potassium, phosphorus, magnesium, sulfur, calcium, fluoride and silicon) and other substances such as pectin, beta-carotene, enzymes and amino acids that attack the free radicals weakening the immune system (18-20).

Prabhu et al. (23) reported that the combined EDTA and apple cider vinegar irrigation provided better results than the $\mathrm{NaOCl}$ group in removing the smear layer in the middle ternary of the root canal. In their study, the stain removal capacity of malic acid in apple cider vinegar was also examined; apple cider vinegar and $5.25 \% \mathrm{NaOCl}$ concentration gave significantly better results than the combined EDTA and $5.25 \% \mathrm{NaOCl}$ concentration. In the study of Estrela et al. (20), $2.5 \% \mathrm{NaOCl}-2 \% \mathrm{CHX}$ gel and EDTA-apple cider vinegar combinations were compared and the 
best result was obtained with EDTA-apple vinegar combination. Similar results were obtained by Zandim et al. (21). In 2011, contrary to the previous studies Dornelles-Morgental et al. (24) found that the combination of $2.5 \% \mathrm{NaOCl}$ and apple cider vinegar was less effective than only $2.5 \% \mathrm{NaOCl}$ or $\mathrm{CHX}$ alone.

\section{Propolis}

Propolis is a resinous adhesive mixture that Apis mellifera bees prepare by collecting materials from different plants in order to preserve the honeycomb structure. More than 160 constituents have been identified in different propolis samples. It usually consists of waxes, resins, water, inorganic compounds, phenolics and essential oils (25). The structure of propolis varies according to the geographic region, climate, vegetation and season of the region. In the studies, it has been discovered that propolis has antibacterial, antiviral, antifungal, anti-inflammatory, regenerative, antihepatotoxic, immunomodulatory, antioxidant, antimutagenic and carcinostatic properties (26-28). Thanks to its properties, propolis is a popular natural product in dentistry as it is in many other fields. It has also been proven in the studies that there is no toxic effect (25). Kujumgiev et al. (29) investigated the antibacterial and antiviral effects of propolis samples from different regions. All samples were reported to be effective against Gram-positive bacteria, fungi; most of the samples also had antiviral activity. Antimicrobial activity of ethanolic extract (PEE) of propolis collected from Kayseri and its environs was investigated and MIC value against $E$. faecalis was measured as $128 \mu \mathrm{g} / \mathrm{mL}$ (30). In the study by Hubbezoğlu et al. (28), the antibacterial activity of propolis samples from Trabzon environs was investigated and it was found that, at high concentrations, it could show antibacterial activity on $E$. coli in the root canals. In contrast to similar studies, Magro-Filho and Carvalho (31) reported that anti-inflammatory properties of propolis solution were more active at a lower concentration, and that was because the flavonoid titers were higher in low concentration samples.

\section{Chitosan}

Chitosan is a natural polysaccharide and composed of a long biopolymer chain of $\mathrm{N}$-acetylglucosamine. Due to its biocompatibility, adhesion, no toxicological activity, and no genotoxic effect, it has been included in research studies of dentistry $(32,33)$. Chitosan is obtained by the deacetylation of chitin in crab and shrimp shells. Chitosan is abundant in nature and possible to be obtained with low production cost; that's why, it has become attractive for various applications (34). The possible uses and advantages of chitosan have been discovered and identified in many fields like medicine and pharmacy (antibacterial and antitumor agent, drug carrier, wound healing accelerator), biotechnology (enzyme and cell carrier, chromatography resin), environmental engineering (water treatment), agriculture (seed preparation), cosmetics and food industry (iron and calcium absorption accelerator, fiber source), yet, studies investigating its further utilization in different areas are still underway (35).

In 2000, Senel et al. (36) examined the antifungal activity of the gel containing $2 \%$ chitosan and found that it was effective against C. albicans. In 2012, Silva et al. (37) evaluated the smear layer removal efficacy of the irrigation agents used in final irrigation after the root canal instrumentation through scanning electron microscopy (SEM) imaging and compared calcium ion concentrations with atomic absorption spectrophotometry. In the SEM analysis, it was observed that $15 \%$ EDTA, $0.2 \%$ chitosan and $10 \%$ citric acid removed the smear layer better than $1 \%$ acetic acid and control group. In other words, a $0.2 \%$ chitosan solution was able to remove the smear layer at low concentration alone, similar results were only obtained with high concentration solutions such as $15 \%$ EDTA and $10 \%$ acetic acid.

\section{Morinda Citrifolia}

Exotic Morinda Citrifolia (Rubiaceae), also known as noni, has been used by the Polynesians for over 2000 years in herbal medicine. Morinda Citrifolia Juice (MCJ) has a wide range of therapeutic effects, including antibacterial, antiviral, antifungal, antiemetic, analgesic, hypotensive, anti-inflammatory and immunostimulant. A number of major components have been identified in the Noni plant such as octoanoic acid, linoleic acid caproic acid, ursolic acid potassium, scopoletin terpenoids, vitamin $C$, vitamin $A$, alkaloids, anthraquinones (such as nordamnacanthal, morindone, rubiadin, and rubiadin1-methyl ether, anthraquinone glycoside), carotene, b-sitosterol, flavone glycosides, Alizarin, amino acids, acubin, L-asperuloside, caprylic acid, rutin, and a putative proxeronine. MCJ is demonstrated to be safe for human consumption through extensive chemical, microbiological, and toxicological analysis and evaluation (38). Murray et al. (39), in 2008, compared Morinda citrifolia, $\mathrm{NaOCl}$, chlorhexidine, and other solutions according to their efficiency in removing the smear layer from the root canal walls. It was observed that the growth of $E$. faecialis was inhibited with Morinda citrifolia juice solution at a concentration of $6 \%$. It was determined that the effective removal of the smear layer was achieved with 6\% CMJ and $\mathrm{NaOCl}$ and with $17 \%$ EDTA for final irrigation. In a study by Kandaswamy et al. (40), in 2010, the antimicrobial activities of $\mathrm{CHX}, 2 \%$ POV-I, propolis, Morinda citrifolia and $\mathrm{Ca}(\mathrm{OH})_{2}$ were compared. $\mathrm{CHX}$ showed better antimicrobial activity and was followed by $2 \%$ POV-I, propolis, Morinda citrifolia and $\mathrm{Ca}(\mathrm{OH})_{2}$.

\section{Aloe Vera}

Aloe vera (Aloe barbadensis miller) is a cactus-like plant that belongs to the Liliaceal family. It is a perennial succulent plant with long and pointed leaves, without stem or with a very short stem, in which large amounts of water are stored in the tissue that is a xerophyte. There are more than 400 species of Aloe, but 
the most popular and widely used species is Aloe barbadensis Miller (commonly referred to Aloe vera). Other species used in health and medicine are included, but are not limited to Aloe arborescens Miller (a member of the asphodelacea family), Aloe andongensis, Aloe ferox, and Aloeperryi Baker (41). Aloe vera has 75 active ingredients including vitamins, minerals, enzymes, sugars, amino acids, organic and inorganic compounds. It has anti-inflammatory, antibacterial, antifungal, antiviral, antioxidant and antiseptic properties. Several studies have shown that Aloe vera has antimicrobial activity against various species, such as S. pyogenes, E. faecalis, C. albicans and S. aureus (42). The study of Tonea et al. (43) showed that the experimental mixture extract of Aloe vera gel with Arctium lappa was able to inhibit highly resistant microorganisms such as $E$. faecalis (inhibition zone diameter: $5.69 \mathrm{~mm}$ ) and C. albicans (inhibition zone diameter: $11.62 \mathrm{~mm}$ ). However, in the study performed by Sahebi et al. (44), Aloe vera solution which cannot show a strong effect against $E$. faecalis is not recommended as a root canal irrigation agent. In another study, it was reported that the antimicrobial activity of Aloe vera progressed slowly and after a longer contact, it had the same level of antimicrobial activity with $\mathrm{Ca}(\mathrm{OH})_{2}$ and Zataria multiflora against $E$. faecalis (45).

\section{Triphala}

Triphala (an Ayurvedic herbal medicine) is a combination of three different medicinal herbs, which are Terminalia bellerica (Bibhitaki), Terminalia chebula (Haritaki) and Emblica officinalis (Amalaki), and it is obtained by drying and powdering those three plants. Triphala contains major four phenolics chemical constituents such as syringic acid, gallic acid, tannic acid and epicatechin along with ascorbic acid (46) In the study of Prabhakar et al. (11), triphala, MTAD, $5 \% \mathrm{NaOCl}$ and green tea polyphenols were evaluated according to their antimicrobial activities on the biofilm layer containing $E$. faecalis. The inhibition zone of Triphala against $E$. faecalis was $24 \mathrm{~mm}$, the MIC was $3.125 \mathrm{mg} / \mathrm{mL}$, and it was found to have antimicrobial activity.

\section{Salvadora Persica (Miswak)}

It is a chewing stick known by different names in different cultures. Its main components include a high ratio of alkaloids, such as salvadorine, trimethylamine, chlorides and fluorides; mid concentrations of silica, sulfur, and vitamin C; and small amount of flavonoids, sterols tannins and saponins. Chemical analysis of $S$. persica has demonstrated the organic compounds, such as pyrrolidine, pyrrole, and piperidine derivatives; glycosides, such as salvadoside and salvadoraside; b-sitosterol and m-anisic acid chlorides, salvadourea, and gypsum; and flavonoids, including kaempferol, quercetin, quercetin rutin, and quercetin glucoside (47). As stated in the 2000 World Health Organization (WHO) consensus report on oral hygiene, miswak (chewing sticks) can be used in oral hygiene motivation (WHO 2000). In the study of Al-Salman et al. (48), it was suggested that $10 \%$ water extract of miswak showed antibacterial effect against both aerobic and anaerobic bacteria in necrotic pulp teeth and thereby could be used as a root canal irrigation solution. Also, in the study by Shingare and Chaugule (49), it was reported that Miswak had antimicrobial properties that could make it an alternative to $\mathrm{NaOCl}$.

\section{Conclusion}

Until now, various synthetic irrigation agents have been investigated and they are still being studied. However, as in medicine, there is an endeavor to return to natural solutions in dentistry and endodontics. In this sense, herbal irrigation solutions also seem to be promising. However, in order to develop ideal herbal irrigation solutions, there is a need for a review of the current literature and more extensive research both in vitro and in vivo types.

\section{Ethics}

Peer-review: Externally peer-reviewed.

\section{Authorship Contributions}

Concept: B.T., K.D., Design: B.T., K.D., Data Collection or Processing: B.T., K.D., Analysis or Interpretation: B.T., K.D., Literature Search: B.T., K.D., Writing: B.T., K.D.

Conflict of Interest: No conflict of interest was declared by the authors.

Financial Disclosure: The authors declared that this study received no financial support.

\section{References}

1. Mohammadi Z, Abbott PV. Antimicrobial substantivity of root canal irrigants and medicaments: A review. Aust Endod J. 2009;35:131-139.

2. Nair PNR, Henry S, Cano V, Vera J. Microbial status of apical root canal system of human mandibular first molars with primary apical periodontitis after "one-visit" endodontic treatmeat. Oral Surg Oral Med Oral Pathol Oral Radiol Endod. 2005;99:231-252.

3. Zehnder M. Root Canal Irrigants. J Endod. 2006;32:389398.

4. Haapasalo M, Shen Y, Qian W, Gao Y. Irrigation in Endodontics. Dent Clin North Am. 2010;54:291-312.

5. Vineet SA, Rajesh M, Sonali K, Mukesh PA. AContemporary Overview of Endodontic Irrigants -A Review. J Dent App. 2014;1:105-115.

6. Hülsmann M, Heckendorff M, Lennon A. Chelating agents in root canal treatment: mode of action and indications for their use. Int Endod J. 2003;36:810-830.

7. Torabinejad M, Shabahang S, Aprecio RM, Kettering JD. The antimicrobial effect of MTAD: an in vitro investigation. J Endod. 2003;29:400-403. 
8. Versiani MA, Pecora JD, Sousa-Neto MD. Update of endodontic irrigating solutions. In: Bettina B, ed. Endodontic Irrigation: Chemical disinfection of the root canal system. 1th ed. Canada. Springer International Publishing Switzerland; 2015:106-113.

9. Popescu I, Popescu M, Man D, et al. Drug allergy: incidence in terms of age and some drug allergens. Med Interne. 1983;22:195-202.

10. Tartari T, Guimaraes BM, Amoras LS, Duarte MAH, Silva e Souza PAR, Bramante CM. Etidronate causes minimal changes in the ability of sodium hypochlorite to dissolve organic matter. Int Endod J. 2015;48:399-404.

11. Prabhakar J, Senthilkumar M, Priya MS, Mahalakshmi K, Sehgal PK, Sukumaran VG. Evaluation of Antimicrobial Efficacy of Herbal Alternatives (Triphala and Green Tea Polyphenols) MTAD, and 5\% Sodium Hypochlorite against Enterococcus faecalis Biofilm Formed on Tooth Substrate: An In Vitro Study. J Endod. 2010;36:83-86.

12. Johnston CS, Gaas CA. Vinegar: Medicinal uses and antiglycemic effect. Med Gen Med. 2006;8:61.

13. Fushimi T, Suruga $\mathrm{K}$, Oshima $\mathrm{Y}$, Fukiharu $\mathrm{M}$, Tsukamoto $\mathrm{Y}$, Goda T. Dietary acetic acid reduces serum cholesterol and triacylglycerols in rats fed a cholesterol-rich diet. Br J Nutr. 2006;95:916-924.

14. Liljeberg $\mathrm{H}$, Björck I. Delayed gastric emptying rate may explain improved glycaemia in healthy subjects to a starchy meal with added vinegar. Eur J Clin Nutr. 1998;52:368-371.

15. Thacker E. The vinegar book. 7th ed. Hartville, Ohio. James Direct Inc; 2005:7-75.

16. Caligiani A, Acquotti D, Palla G, Bocchi V. Identification and quantification of the main organic components of vinegars by high resolution $1 \mathrm{H}$ NMR spectroscopy. Anal Chim Acta. 2007;585:110-119.

17. Costa D, Dalmina F, Irala LED. The use of the vinegar as a chemical auxiliary in endodontics: a literature review. Rev Sul-Bras Odontol. 2009;6:185-193.

18. Estrela C, Holland R, Bernabé PFE, de Souza V, Estrela CRA. Antimicrobial potential of medicaments used in healing process in dogs' teeth with apical periodontitis. Braz Dent J. 2004;15:181-185.

19. Estrela C, Lopes HP, Elias CN, Leles CR, Pécora JD. Cleanliness of the surface of the root canal of apple vinegar, sodium hypochlorite, chlorhexidine and EDTA. Rev Assoc Paul Cir Dent. 2007;61:177-182.

20. Estrela CR, Estrela C, Cruz Filho AM, Pécora JD. ESP substance: Option in endodontic therapy. J Bras Endod. 2005;5:273-279.

21. Zandim DL, Corrêa FOB, Sampaio JEC, Rossa Júnior C. The influence of vinegars on exposure of dentinal tubules: a SEM evaluation. Braz Oral Res. 2004;18:63-68.

22. Yagnik D, Serafin V, Shah A. Antimicrobial activity of apple cider vinegar against Escherichia coli, Staphylococcus aureus and Candida albicans; downregulating cytokine and microbial protein expression. Sci Rep. 2018;8:1732.
23. Prabhu SG, Rahim N, Bhat KS, Mathew J. Comparison of removal of endodontic smear layer using $\mathrm{NaOCl}$, EDTA, and different concentrations of maleic acid - a SEM study. Endodontology. 2003;15:20-25.

24. Dornelles-Morgental R, Guerreiro-Tanomaru JM, de FariaJúnior NB, Hungaro-Duarte MA, Kuga MC, Tanomaru-Filho M. Antibacterial efficacy of endodontic irrigating solutions and their combinations in root canals contaminated with Enterococcus faecalis. Oral Surg Oral Med Oral Pathol Oral Radiol Endod. 2011;112:396-400.

25. Mohammadzadeh S, Shariatpanahi M, Hamedi $M$, Ahmadkhaniha R, Samadi N,Ostad SN. Chemical composition, oral toxicity and antimicrobial activity of Iranian propolis. Food Chem. 2007;103:1097-1103.

26. Seidel V, Peyfoon E, Watson DG, Fearnley J. Comparative study of the antibacterial activity of propolis from different geographical and climatic zones. Phytother Res. 2008;22:1256-1263.

27. Hepşen IF, Tilgen F, Er H. Propolis: Medical properties and ophthalmologic use. J Turgut Ozal Med Cent. 1996;3:386391.

28. Hubbezoğlu I, Özan Ü, Sümer Z. Effects on escherichia coli of solutions containing propolis and potassium titanium phosphate laser in root canal irrigation. J Dent Fac Atatürk Uni. 2011;21:15-21.

29. Kujumgiev A, Tsvetkova I, Serkedjieva Y, Bankova V, Christov R, Popov S. Antibacterial, antifungal and antiviral activity of propolis of different geographic origin. J Ethnopharmacol. 1999;64:235-240.

30. Kaya Gündüz E, Ozbilge E, Albayrak S. Antimicrobial Activity of the Ethanolic Extract of Kayseri Propolis. Selcuk Med J. 2012;28:209-212.

31. Magro-Filho O, Carvalho AC de. Topical effect of propolis in the repair of sulcoplasties by the modified Kazanjian technique. Cytological and clinical evaluation. J Nihon Univ Sch Dent. 1994;36:102-111.

32. Costa EM, Silva S, Costa MR, et al. Chitosan mouthwash: Toxicity and in vivo validation. Carbohydr Polym. 2014;111:385-392.

33. Senel S, Ikinci G, Kaş S, Yousefi-Rad A, Sargon MF, Hincal AA. Chitosan films and hydrogels of chlorhexidine gluconate for oral mucosal delivery. Int J Pharm. 2000;193:197-203.

34. Peter MG. Applications and environmental aspects of chitin and chitosan. J Macromol Sci. 1995;32:629-640.

35. Jeon YJ, Shahid F, Kin SK. Preparation of chitin and chitosan oligomers and their applications in physiological functional foods. Food Rev Int. 2000;16:159-176.

36. Senel S, Kremer MJ, Kaş S, Wertz PW, Hincal AA, Squier CA. Enhancing effect of chitosan on peptide drug delivery across buccal mucosa. Biomaterials. 2000;21:2067-2071.

37. Silva PV, Guedes DFC, Nakadi FV, Pecora JD, Cruz-Filho AM. Chitosan: a new solution for removal of smear layer after root canal instrumentation. Int Endod J. 2013;46:332338. 
38. Wang MY, West BJ, Jensen CJ, et al. Morinda citrifolia (Noni): a literature review and recent advances in noni research. Acta Pharmacol Sin. 2002;23:1127-1141.

39. Murray PE, Farber RM, Namerow KN, Kuttler S, Godoy FG. Evaluation of Morinda citrifolia as an endodontic irrigant. J Endod. 2008;34:66-70.

40. Kandaswamy D, Venkateshbabu N, Gogulnath D, Kindo AJ. Dentinal tubule disinfection with $2 \%$ chlorhexidine gel, propolis, morinda citrifolia juice, $2 \%$ povidone iodine, and calcium hydroxide. Int Endod J. 2010;43:419-423.

41. Guo X, Mei N. Aloe vera: A review of toxicity and adverse clinical effects. J Environ Sci Health C Environ Carcinog Ecotoxicol Rev. 2016;34:77-96.

42. Wynn RL. Aloe vera gel: Update for dentistry. Gen Dent. 2005;53:6-9.

43. Tonea A, Badea M, Oana L, Sava S, Vodnar D. Antibacterial and antifungal activity of endodontic intracanal medications. Clujul Med. 2017;90:344-347.

44. Sahebi S, Khosravifar N, Sedighshamsi M, Motamedifarc M. Comparison of the Antibacterial Effect of Sodium Hypochlorite and Aloe Vera Solutions as Root Canal Irrigants in Human Extracted Teeth Contaminated with Enterococcus Faecalis. J Dent (Shiraz). 2014;15:39-43.
45. Abbaszadegan A, Sahebi S, Gholami A, et al. Timedependent antibacterial effects of Aloe vera and Zataria multiflora plant essential oils compared to calcium hydroxide in teeth infected with Enterococcus faecalis. J Investig Clin Dent. 2014;7:93-101.

46. Jagetia GC, Baliga MS, Malagi KJ, Sethukumar Kamath $M$. The evaluation of the radioprotective effect of Triphala (an ayurvedic rejuvenating drug) in the mice exposedto gamma radiation. Phytomed. 2002;9:99-108.

47. Halawany HS. A review on miswak (Salvadora persica) and its effect on various aspects of oral health. Saudi Dent J. 2012;24:63-69.

48. Al-Salman TH, Al-Shaekh Ali MG, Al-Nu'aimy OM. The antimicrobial effect of water extraction of salvadora persica (miswak) asa a root canal irrigant. Al-Rafidain Dent $\mathrm{J}$. 2005;5:33-36.

49. Shingare $P$, Chaugule V. Comparative Evaluation of antimicrobial activity of miswak, propolis, sodium hypochlorite and saline as root canal irrigants by microbial culturing and quantification in chronically exposed primary teeth. Germs. 2011;1:12-21. 